\title{
Thormation
}

Nordic Journal of Art and Research

ISSN: $1893-2479$

www.artandresearch.info

\section{Drawing as a "head over heels" thought process: understanding the meaning of fragmentation in the act of drawing}

\author{
Christian Montarou ${ }^{1}$ \\ Institute of landscape planning, Norwegian university of life sciences, Ås
}

\begin{abstract}
This article examines the significance of free-hand drawing from perspectives that go beyond the technical considerations of perspective, proportion and chiaroscuro. These perspectives include the artist's mental process while drawing, exploring the relationship between the artist and the artwork in order to understand the significance of fragmentation as a creative element in this process. Another perspective examines the conditions for seeing and drawing, that is, the cognitive and psychological aspects of the act of drawing. In addition, various theoretical concepts are applied to analyse the creative process. References to psychoanalysis are used to explain the state of fragmentation inherent in the condition of human beings as subjects, while language theory is applied to reveal the motives underlying the need for self-expression through drawing. Theories about mental development during childhood are applied to shed light on artistic practice and increase our understanding of the psychological mechanisms behind creativity. Finally, the "creative mode" as such is questioned: How can this state of mind be induced and what is its relevance for encouraging creative thinking? The theoretical approach is illustrated with images taken from student work at the Department of Landscape Architecture and Spatial Planning at the Norwegian University of Life Sciences (UMB), as well as my own paintings and one historical painting.
\end{abstract}

Keywords: Tacit knowledge, embodied mind, schemata, imago, phantasm, creative mode, metaphor, visualisation, fragmentation, identification, simulacra.

\footnotetext{
${ }^{1}$ ILP, box 5003, NO-1432 Ås. E-mail: christian.montarou@umb.no
} 


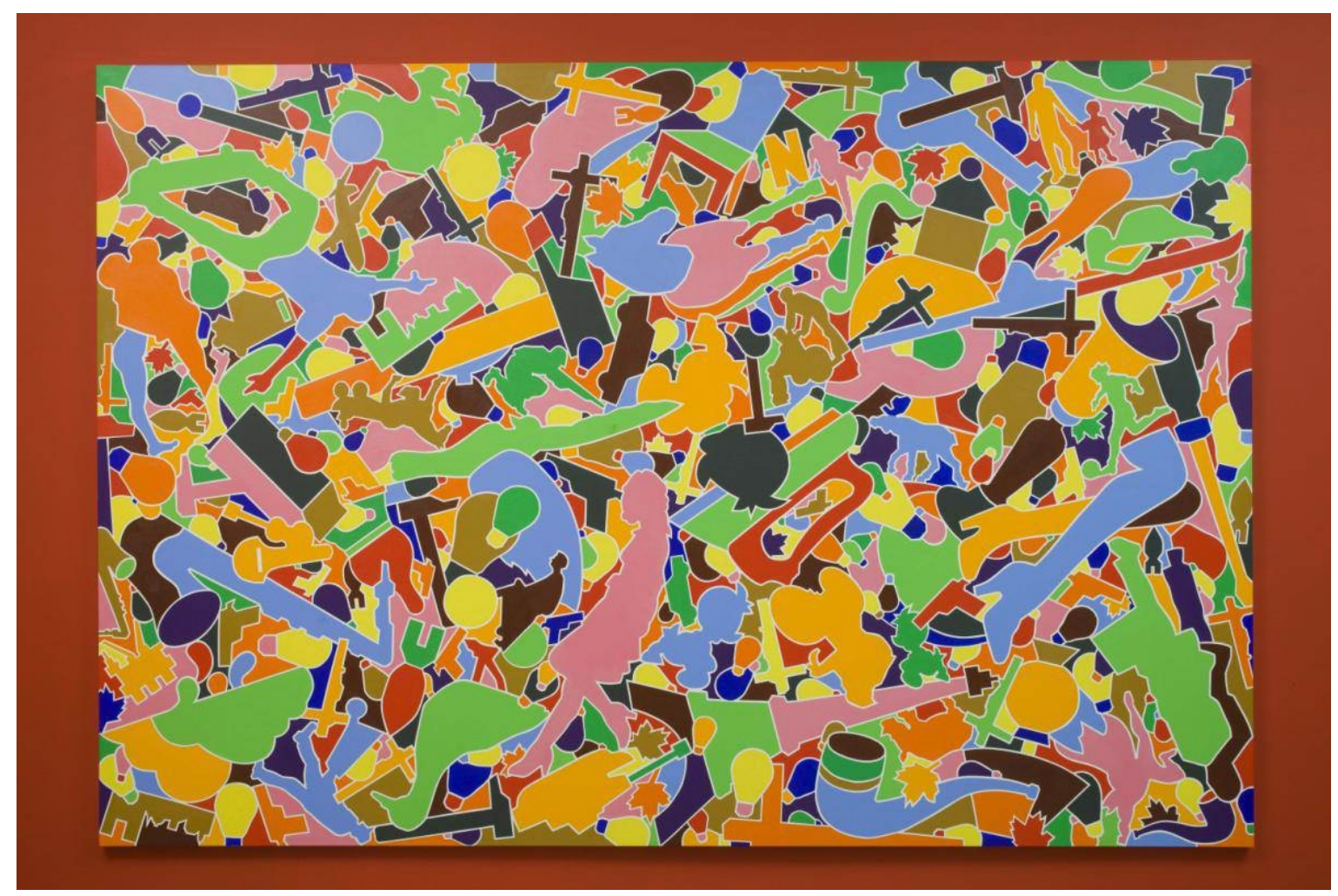

Figure 1. Christian Montarou. Continuum I, 2010. Acrylic on canvas 200 x $295 \mathrm{~cm}$.

\section{Introduction}

How does an artist assemble fragments of sensory stimuli to produce visually meaningful units in a drawing? This complex and partly subconscious phenomenon can be described as a mental learning process through which new insight is obtained. In trying to understand this process, I am inspired by several different concepts. One is tacit knowledge, i.e. unarticulated knowledge that is often impossible to convey in words (Polanyi, 1962). It refers to inherent knowledge that is integrated in our bodies as a part of the personality. This stands in contrast to explicit knowledge, which is characterised by a more tangible understanding that can readily be expressed through words. Since tacit knowledge is linked to the body and the five senses, it is individual and particular (rather than general) in nature. As an artist and teacher, I have experienced how tacit knowledge can be expressed through skills such as drawing (Montarou, 2011). An understanding of these two different types of knowledge, when applied to drawing, suggests the operation of an interactive process whereby different levels of consciousness are combined to produce new insight. This process is quite unlike that suggested by traditional views of theory and practice.

Another source of inspiration is the concept of the embodied mind (Wilson \& Foglia, 2011). The brain is incapable of thought without the body, let alone the body without the brain. The senses are not the only source of knowledge by which abstract categories develop to live their own lives in the brain, separated from the body. The brain is embodied and starts to build up and develop kinaesthetic models of movement from the time of birth. In the "space" between the body and the mind, the child accumulates basic patterns; rudimentary structures which form the reference of later cognitive processes. Embodied knowledge is transferred through metaphors to produce meaning, thus extending 
the body's biological and physiological limits. In this context metaphors mean far more than poetic figures of speech: "The essence of metaphor is to understand and experience one thing from another" (Lakoff \& Johnson, 1980). Merleau-Ponty, the French philosopher, was the pioneer who rethought the traditional understanding of the separation between the body and the mind, emphasising the significance of the body both as a subject and as an object in our experience of the world. In other words, there is a duality in both being a body and having a body (Merleau-Ponty, 1945). Body experiences are memorised in mental structures called schemata (Carman, 1999) that are used when encountering similar situations.

My third source of inspiration is an interest in the hidden aspects of the creative process. A fascinating question to me is: What happens when experiential knowledge related to deep layers of the body spring to mind in a fraction of a second during the interpretation of a sketch with a living model? The Norwegian psychiatrist Finn Skarrderud writes that the competence to mentalise concerns the mind's capacity to produce images of reality. This capacity implies both an awareness of images as interpretations and that they in turn represent a parallel reality made up of a symbolic language differing from "primary reality" (Skårderud 2008). The failure to mentalise is defined by Fonagy as an inability to symbolise, i.e. to create meaning by connecting form (signifier) and content (signified) (Fonagy 2002). How we "formulate" our perception of "primary" reality by connecting fragments of sensory stimuli, is an unconscious process happening so fast that reflection can only follow after. An artist, in contrast, lingers at the moment of perception itself. As a creator he or she has to experiment with shape in relation to linguistic categories, in order to produce new meaning. To draw is to create a signifier from scratch that gives the possibility to both mentalise and de-mentalise, in other words to connect and disconnected form and content, experimenting between primary reality and its interpretation as an inherent part of the creative process.

These sources of inspiration that relate the unconscious to the body and treat the cognitive process as a creative mental and bodily activity are useful tools for understanding the practice of drawing as such. Within this practice, the ability to access body knowledge is dependent on entering into a creative mode that breaks down the routine of "head thinking" and opens the way to a "head over heels" thought process.

\section{Part 1: Theoretical context and fragmentation}

\section{The gaze as a mirror}

What is "representation"? In visual art, a representation is an image which represents, and replaces an absent object. What the eyes see is not identical with what the brain says that the eyes see. This indicates a gap between consciousness and the body.

Jacques Lacan's theory of the mirror stage explains the significance of images and gaze in the development of the young child's fragmented existence, from the maternal symbiosis to separate identity both in the meaning of "body gestalt" and mental structure. The mirror stage theory focuses on the gaze as a mirror that constitutes the self in the early stage of the child's ego. According to Lacan, the process of acquiring "gestalt" starts when the child is overwhelmed by the initial pain of no longer being a part of the mother's body and is forced to produce a "phantasm" to survive that pain (Lacan, 1949). 


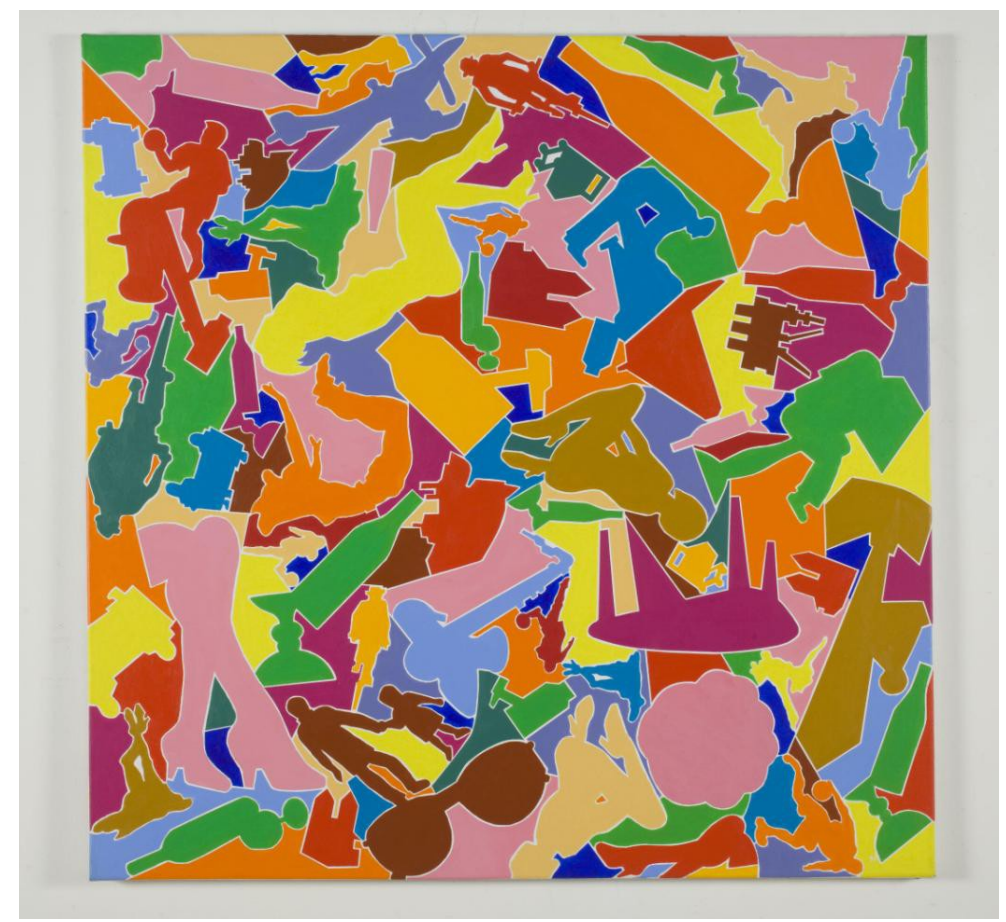

Figure 2. Christian Montarou. Continuum II, 2010. Acrylic on canvas, 80 x $80 \mathrm{~cm}$.

Some linguistic background may be helpful for understanding the content of the psychoanalytical concept of "phantasm", which in this instance is concerned with the child's situation at its secession from symbiosis with the mother. This profound secession in infancy can paradoxically be compared to a near-death experience. The first translators of Sigmund Freud's writings into French chose to translate the German word" Phantasie" (imagination) as "fantasme", which is a combination of two French words: "phantasme" and "fantasie", meaning "hallucination" and imagination, respectively.

In his book "L 'espace litteraire" Maurice Blanchot sheds new light on the concept of imagination by discerning between two "versions of imagination". In the first version, the "image" being imagined is mimetic, referring to an existing real-world object. Through his experience of imagination in poetry and literature, Blanchot argues that there is also an extended second version of imagination. In this version, the viewer's overwhelming fascination with an object dissolves the mimetic order described above, erasing the distance between the object and the viewer (Blanchot, 1955).

For Blanchot, the cadaver is the best example of the fascinating and ambiguous status of the image in the perception of reality. The cadaver possesses a unique transitional quality as both a bridge and a boundary between life and death - or presence and absence - similar to the way an image simultaneously unites and separates the subject and the perceived reality.

The paradoxical near-death experience referred to above begins when the infant produces an imago of the mother through visualisation (Jung, 1933). This can be compared to a person lost in the desert producing a mental picture of an oasis in order to "survive". The imago as an unconscious mental representation of the mother's body will not be enough to enable the child to endure the feeling of emptiness and anxiety that it experiences. The imago does not only refer to the mother's physical body, but also to something more abstract, her "goodness". The development of an imago provides a distance in the relation between the child and the mother as separate identities. 


\section{What is creativity?}

The psychologist Anton Ehrenzweig analyses the creative process from the perspective of psychoanalysis and by comparing the three stages of the process with Melanie Klein's object relations theory (Ehrenzweig, 1967). He suggests that the structure of this process follows the same basic pattern for the child as for the artist. The first stage is the initial fragmentation experienced by the individual. The infant does not distinguish between the mother and itself. Instead it separates the experience of the "good mother" and the "evil mother" and experiences the world in a fragmentary manner. Ehrenzweig relates this stage to the chaos of the early stages of an artist's work, which is often a very stressful period full of insecurity and anxiety for the artist. Ehrenzweig calls this stage, in which the artist is unable to accept criticism, the "paranoid-schizoid position". So far, the artist and the individual parts of the artwork have not undergone a process of identification that will transform these parts into a unifying whole. The artist experiences conflicting feelings about him or herself, his or her ability to resolve the underlying creative problem and the work as such.

The second stage of the creative process is known as the "depressive position". This corresponds to the point where the child in Melanie Klein's theory integrates its earlier projections of unbearable emotions. The "good mother" and the "evil mother" are internalised as the same person and the child experiences its separation from the mother, i.e., identification has taken place. This corresponds to the position of the artist, who has now discovered the counterpart of his or her work. In a painting for example, the negative, interstitial areas have been internalized into one unified image. The picture has acquired meaning as a visual-linguistic statement. The distance created from the primary object (the mother or the picture) causes the symbiotic condition to be replaced by a feeling of depression for both child and artist.

The following day the artist will be able study his or her work as if it were someone else's product. The conflicting emotions of the earlier position go through a process of reconciliation, based on the premises of the positive feelings. For a while, the artist's predominant emotions are self-confidence and trust in everything going well. The artist experiences that the picture begins to live its own life and develop its own demands. A dialogue has commenced that may be hoped to turn into a fruitful exchange.

Out of an initial meaningless chaos of shapes, the artist is now able to imagine and organise fragments, composing a whole that represents more than the sum of its parts. This whole will be recognised by the artist as the coherence of his or her mind. A pictorial space is built up through a process of analogous transference to contain an expression of the artist's mental space.

The third stage proposed by Ehrenzweig is not based on the work of Melanie Klein, but on that of Freud. This position is categorised as the "manic-oceanic position", also known as religious fervour. This condition represents a higher level of consciousness where the artist perceives his or her relationship with the artwork as a dialogue between two persons. This, in turn, creates the preconditions for introducing subconscious material. At this stage, the artist has moved beyond conventional aesthetic definitions of what is "good" or "bad", resulting in personal, original, creative work. Consequently, Ehrenzweig claims that creative acts constitute a dynamic process that switches between mental projection, distancing and re-introduction, while perception alternates between focal and non-focal vision. 


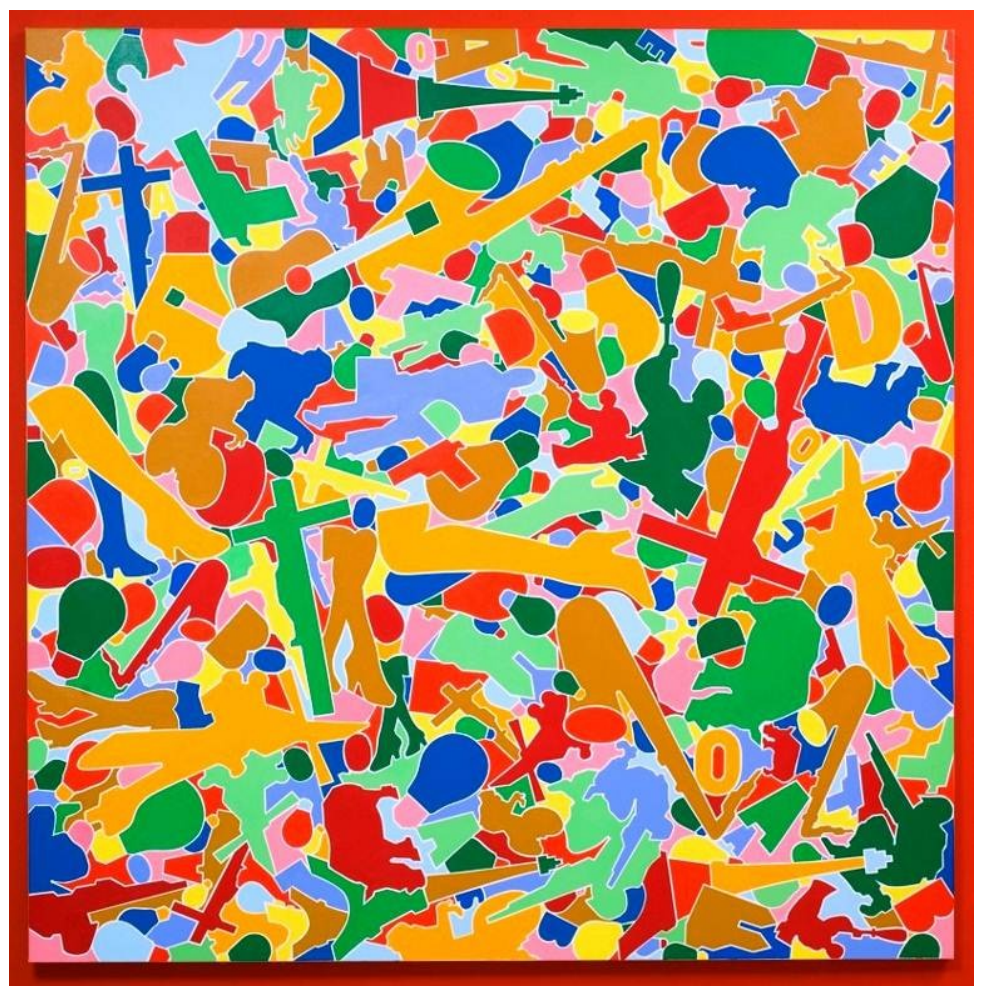

Figure 3. Christian Montarou. Continuum IV, 2010. Acrylic on canvas 200x200 cm

\section{Identification and drawing}

The process of identification in drawing takes place on several levels. The first involves artistic choices such as quality of line, light and shade, and methods of depicting planes and movement. Choices of materials, tools and technique, such as charcoal, pencil or ink, are also included in level one. Both as optical and tactile stimuli, these elements have qualities that the artist can identify with. The second level addresses figurative mental categories in the choice of motif. The art theorist Ernst Gombrich demonstrated the importance of recognition schemata in the representation of motif a. His reflections on, among other things, mediaeval representations of animals, demonstrate how vision, identification and representation interact and reveal the presence of identification models (Gombrich, 1987). Gombrich's concept of "picture schemes" has been extended to apply both to perception (seeing and recognising) and to representation (drawing a motif) as "experiential schemata" and "depiction schemata" (Kjørup, 1995). The former help us to interpret experiences so that they become meaningful, while the latter help us to translate our experience of reality into, for instance, graphic signs such as drawings.

The concept of schemata has been brought forth by several theoretical traditions with varying, and contrasting points of view. Put simply a body schema is the unconscious stored body experience that depends on sensory development and the body's ability to move in space. Schemata are abstract mental structures that organise perceived sensory and sensory-motor stimuli. As such, they constitute a core of knowledge that can be adapted to any number of situations. The basic elements of intellectual activity are not sensations, perceptions or actions, but schemata. Viktor Lowenfeld has described how depiction schemata develop in children from the age of two (Lowenfeld 1947). It is worth noting how the schemata defined by Lowenfeld as a "visual concept" are the same as the "shared language" which every child uses, based on its developmental level. The development of the schemata is partly a social process in which children watch and learn from each other. To see something "as" is an example of the 
human being's dependence on "linguistic" references. This "as" is the schema's interpretation that interprets and transforms the "motif". Tom Sandkvist explains what we actually see in perception as "the interpretation of an interpretation" (Sandkvist 94).

The semiotician Bernard Darras discusses the relationship between schemata and similes (optical similarity). He compares the relationship between schemata of figurative thinking (linked to rational categories and concepts), with schemata of visual thinking, (connected to optical references and perceptions). He defines the work of cognitive recognition that goes between schemata and similes as a semiotic process between the distal stimulus (the external object), the proximal stimulus (for instance patterns of light wave lengths that mark the retina as indices) and schemata that represent the cognitive categories. The visual or auditory sensory construction that takes place inside the brain immediately loses its reality when it is incorporated into the abstraction of a concept. Thinking in images is a visual activity involving a set of visual information and their cognitive processing. The entire drawing repertoire of visual building blocks - lines, areas, perspective, technique, representational shapes on a two-dimensional surface - are taken into use in order to "interpret" a motive in the production of a graphic analogy (Darras 1998).

The line is a basic element of drawing, offering a snapshot of the presence of the self at some point in the creative process. As the Norwegian painter Christian Krogh said: "Someone who is drawing is working with lines. Lines do not exist. What exists is inside and outside" (Krogh, 1917: 2). The body exists in the gap between perception and the outer world: the self as a mental reality is located between the categories of language, which create distance from the bodily experience, and the signals from the body itself. What is more, the vulnerability that is exposed as a stream of consciousness between these opposites is an important part of the drawing process. In other words, there is a displacement in time that takes place between the act of seeing and the act of drawing a line. Lines exist only as simulacra: a trace that resemblances what it describe without having the meaning of it.

\section{An "other" look at drawing}

Drawing has traditionally been defined as the ability to see and register the external world using the technical skills available to the artist. However, the French philosopher Jacques Derrida has suggested a point of view on drawing that both accords with the psychoanalytic theories described above and differs radically from the traditional view of drawing as related to the visual perception of the external world (Derrida, 1990).

Derrida examined the origins of the human desire to use lines for the purposes of expression. From Derrida's perspective the artist is blind. The underlying motivation for graphic representation does not relate to visual perception, but to memory. It is the primary object's absence that "haunts" the memory. The artist's blindness is the result of the "blind spot" of consciousness, which sublimates this painful absence by projecting desire onto a surrogate, namely the present sign of figurative language. In other words, the line reflects the artist's will rather than the observable contours of the motif. This will, in turn, is associated with subconscious memory, namely that of the loss of and separation from Mother Nature.

Many artists have been inspired by Greek mythology. One example is the painter Joseph Benoit Suvée, who in 1791 made a painting based on a mythological motif (Fig. 4). The painting shows a young woman from Corinth about to be separated from her lover. In the Greek myth, she traces the outline of his shadow on the wall moments before his departure. Her father, a potter, uses this tracing 
as the basis for a clay portrait of the absent lover. In Greek mythology, this myth was used to explain the origins of drawing and portraiture (both painted and sculpted).

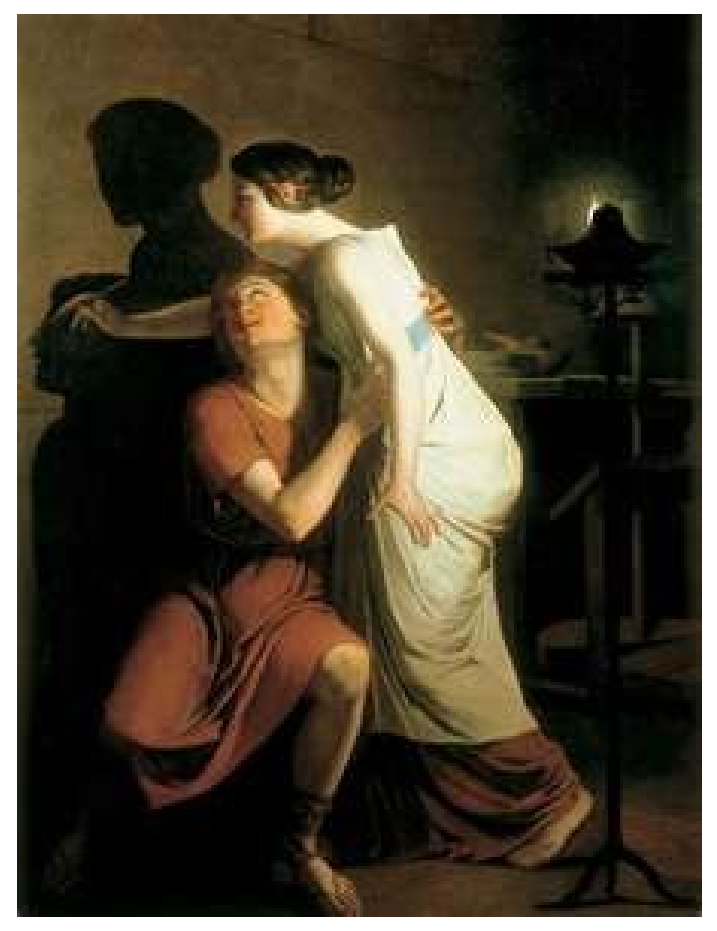

Fig. 4. Painting by Joseph Benoit Suvée, 1791.

In the myth, the only way the young woman could bear the pain of her lover's absence was by recreating him as an image. Suvée's painting implies that a desire to remember is the inspiration for drawing. This perspective contrasts with the more traditional view, which understands visual perception and the artist's craftsmanship and ability to reproduce "reality" as the foundation of art. As the story depicted by Suvée in this illustration suggests, the origins of representation can be related to the absence and invisibility of the model. Last but not least, the sublimation of desire, the woman's longing for her lover, is portrayed as the motivational point of departure for symbolic representation. Jacques Derrida used this image to indicate the hidden aspects of figurative language (Collins \& Mayblin, 1998).

According to Derrida (1990), the artist is blind on three levels. Because of the temporal displacement between the acts of registration and recording, the artist cannot see the model while he or she is actually drawing. In other words, the artist must depend on memory both to depict what he or she has just seen and noted, but also in the longer term. This is the first level of blindness, where viewing objects gives way to the act of drawing lines. The second level of blindness is when the line leaves traces that become invisible in order to make way for the drawing itself, with its subdivisions of format and interstitial areas. The third level is when "the drawing itself", created while the second level of blindness was prevailing, is no longer visible because it has fused with the symbolic meaning of the drawing.

Derrida's description of blindness linked to the depiction process in producing a drawing show a parallel to Darras explanation of the semiotics of visual perception mentioned earlier. The concept of blindness derived from long-term memory refers to cultural schemata that govern the artist's perception, albeit subconsciously. 


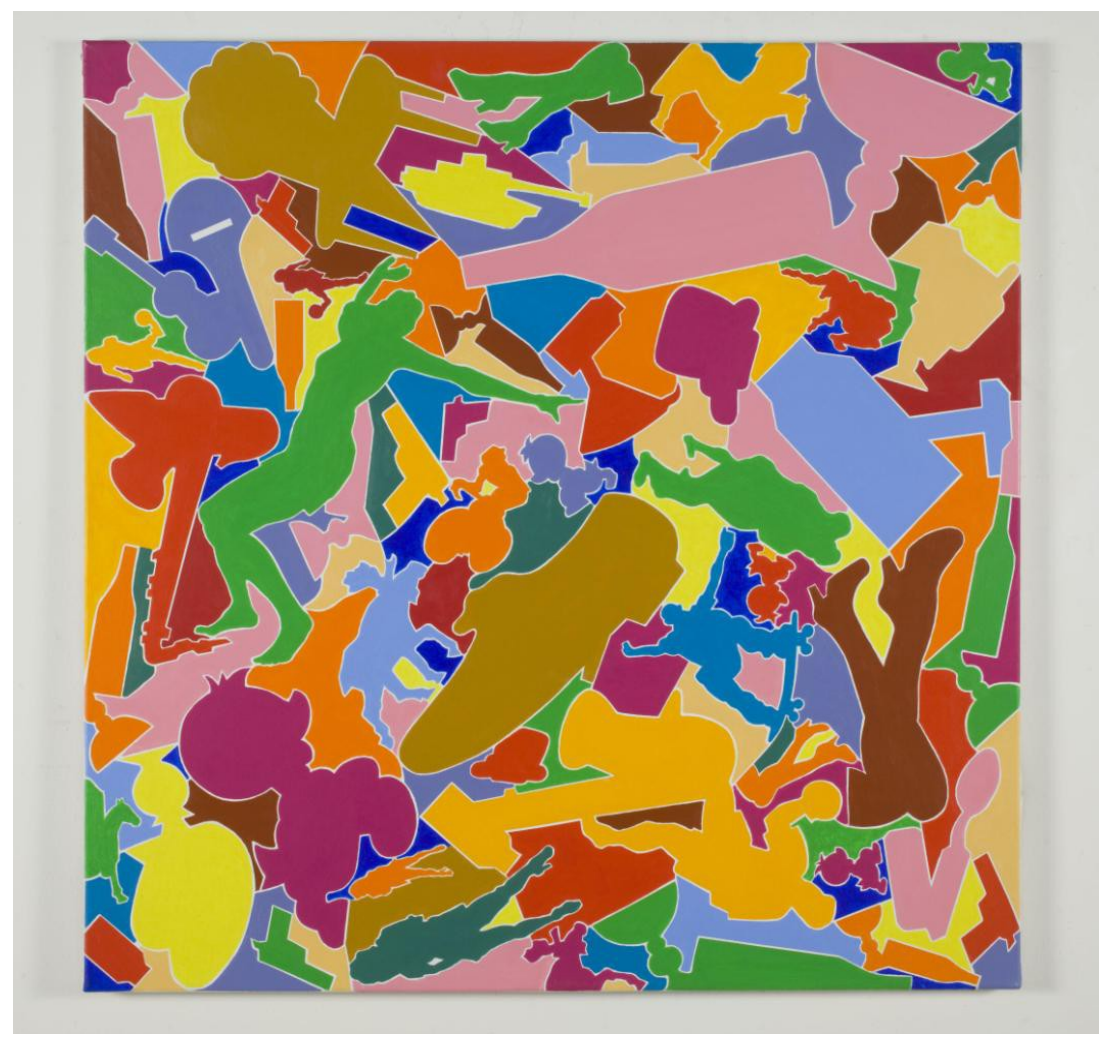

Figure 5. Christian Montarou. Continuum 6, 2010. Acrylic on canvas 80 x $80 \mathrm{~cm}$.

\section{Part 2: Fragmentation as a creative method in drawing}

\section{Deconstruction and construction}

The desire to destroy something that is in existence may seem negative. Nevertheless, destructive acts can have positive consequences if they are part of the process of creating something new. Fragmenting and deconstructing something already in existence then becomes a stage in the necessary restructuring of a motif. Part of this process involves emptying the motif of its normal, symbolic content and perceiving its forms individually, as disconnected from meaning, simply as forms. This must be done at the same time, since one views the disconnected forms both "figuratively" and as related to meaning, such as when hair is regarded both as an image of hair and as wavy lines. This goes beyond the distinction in Gestalt theory between forms and background. The process has also been applied systematically in collective drawing works (Fig. 9).

The artist has to transform his or her aesthetic material into something more malleable, between reality and fiction. In psychoanalysis, this is called a transitional object. The transition between the actual motif and the sign for the motif serves to release creativity by allowing the artist to appropriate the motif in his or her own manner. This process transforms the act of perception into a creative act which differs from the straightforward consumption of stimuli. One part of this process has elements of partial dissociation, (see Fig. 6), but also includes a process of integration of the shapes of figurative language. The mind's ability to create mental images of physical reality that leads to symbolisation is expressed here as an original drawing. In the article on "mentalisation" mentioned earlier, Finn Skårderud refers to the Fonagy tradition's two definitions of the failure to mentalise: 
1) "Mental equivalence" refers to a primitive symbolisation flaw. This is a flaw that occurs when reality is expressed simply as it is, without room for interpretation on the basis of linguistic schemata, i.e., "seeing as".

2) In developmental psychology, the "imaginary mode" is an alternative way in which the child experiences reality, which is linked to playing and represents a disjuncture between internal and external realities. Language is disconnected from feelings, experiences and memories. The child uses language effortlessly and without any constraints. In a child's development, these two forms of experience are normally integrated into a reflexive mode or mentalisation, in which thoughts and feelings can be experienced as representations (Skårderud, 2008).

Similar forms of experience become part of the drawing process, but the motivation, understanding and context are quite different. The way this experience is ultimately integrated into the final result depends on the motivation for creating meaningful analogies. Sometimes, a process of dissociation and deconstruction can make sense in itself, as in the paintings shown in this text (see Figs. 1, 2, 3 and 5), where the apparent lack of meaning becomes a metaphor for the human condition in today's society, overloaded as it is with informational stimuli.

The interpretation of shapes in the paintings is transformed into pure fantasy because the elements and the totality are composed specifically so that they do not integrate with each other. Linguistic relationships that produce meaning are broken, causing the picture signs to live their own lives as pure fiction, detached from real phenomena - something comparable to the "imaginary mode" describe above.

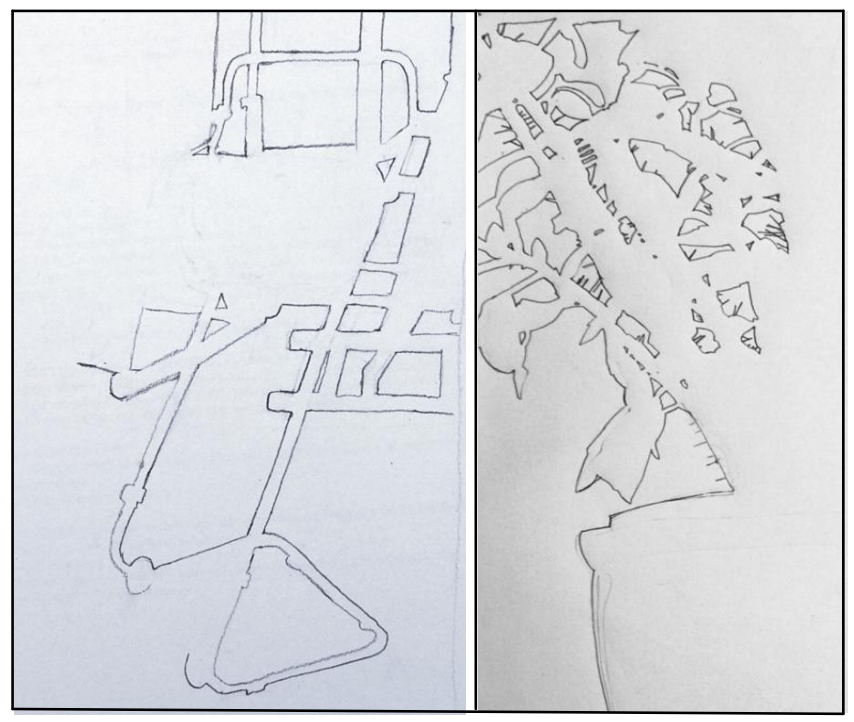

Figure 6. Anonymous student works, 2003. Two examples of fragmentation of the motif's forms.

\section{Parts and puzzles}

In addition to an abstraction of shapes' content, the continuous working process causes the artist to see these shapes independently of their position in space. As a result they are translated into surfaces, on the "conditions" of the eye. The shapes are "puzzled" together onto an imaginary transparent plane, coextensive with the drawing surface, known by artists as the picture plane. The shapes will now become part of a puzzle that starts off as disconnected and two-dimensional, but where all the fragments after a period of incubation will find their appropriate place. The trick is to "turn off" the 
brain's schematic way of thinking in order to see the shapes independently of the automatic visual process that converts objects to constant forms and sizes and thus see the shapes as they are, with all the deformations caused by factors such as distance.

The most demanding aspect of motif fragmentation is the self-confidence required to release the work from the control of the analytical part of the brain. The artist needs to dare to engage in a chaotic fragmentation of the motif: a process that runs counter to the usual "labelling" involved in conceptual thinking. The artist must expose himself to a taxing experience of "visual wandering", concentrating fully on each step of the process without worrying about how it will end up. Examples of this experience can be seen in the paintings reproduced with this text that expose the viewer's eye to a perceptual strain. The eye is met only by an unstable and discontinuous stream of pictorial materiality, generating a push-and-pull effect that makes the surfaces vibrate as the body's pulse rate increases. Furthermore, this materiality of shapes and colours is defined by lines cutting up the entire surface into countless different and adjacent fragments of space. The size of the paintings, which in many cases exceeds the viewer's body dimensions, fig. $1(200 \times 295 \mathrm{~cm})$ and fig. $3(200 \times 200 \mathrm{~cm})$, prevents us from seeing the whole painting from close at hand. On the contrary, it creates an intimacy whereby we are embraced by the picture's presence, almost becoming a part of it.

\section{The body, mind and flow}

The work process described above can only be achieved if the artist is able to find the right mode or mental attitude. The artist needs to alter the relationship between brain and body in order to reduce the customary distance created by language. The objective is to enter a state of attentive presence to the body, a state that can be described as a disengagement of the normal, rational functions of the sensory apparatus. When in this creative drawing mode, there is a momentary suspension of the duality of body and mind. As a result, the past, present and future begin to float, allowing a large amount kinaesthetic image schema, i.e., pre-verbal knowledge, to be articulated in the form of metaphors.

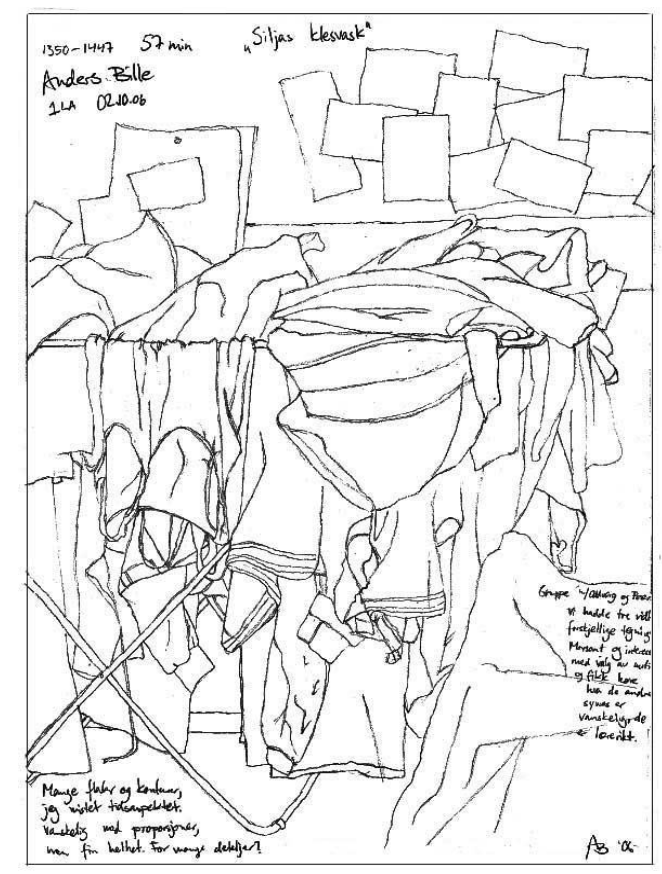

Figure 7. Student work by Anders, 2006. (Use of fragmented interstitial areas to see the motif as a whole.) 
A characteristic of this condition is that all sense of linear, mathematically measured time is erased. The artist seems to become at one with time - "fully present" in the situation - and experiences a moment of timelessness. This allows the body to play a different role in the process of perception; the anatomical, functional and rational body that creates meaning becomes less relevant. By partly "turning off" the capacity for analytical thought, the brain ceases to perceive the body (as it usually does) as separate from its surroundings. Instead the brain focuses on the actual and specific body. Everything appears to take place simultaneously and no longer as a series of events involving cause and effect. To a greater extent than otherwise, the body is experienced as being "at one" with the surroundings and "in flow" (Csikszentmihalyi, 1996).

The non-focal type of perception associated with this condition provides us with an insight into what is "seen" prior to the brain's registration of recognisable motifs in accordance with its index of perceptive schemata. Traces of light registered on the retina are seen as abstract shapes without hierarchies of meaning. The diffuse area between the pre-verbal and the verbal/interpreted sign, which has been obscured by naturalistic painting, can be experienced as a fact: nothing is in focus in the field of vision. This is illustrated by the paintings of Cézanne: motifs' contours are left unfinished with colours locked in by lines drawn around the shapes or the paintings' perspective and composition are locked by the separation of the motif from its surrounding forms. Instead, he depicts the visual as it takes shape (Sandqvist, 1990).

\section{Moving on}

Having used this creative mode in order to achieve a deconstructive/constructive relationship with the motif, it is especially interesting to learn more about one's own "logic of shapes", i.e., the process by which one juxtaposes fragments of shape and intervals of space, as described above (see Figs 1, 2, 3, 5, 6 and 7). The objective is no longer to make the drawing resemble the object, but to become more aware of what the act of drawing in itself entails. This is a process that has a special "heuristic" logic (Fustier, 1975), with inherently flexible developmental rules.

An interactive displacement between observation and the drawing of lines is typical of the drawing process. This displacement indicates that information is being gathered in temporary sequences that follow one another in the artist's short-term memory, before being used for further steps by being projected in the drawing. Unlike in linear, logical spoken or written statements, in which meaning arises as a result of a logical process of sequential ordering, all information is presented simultaneously in a drawing. This requires creative handling of the layered process of accumulation necessary to achieve a synthesis of informative elements. In a conversation, speech develops freely and - depending on the speaker's imagination and alertness - will include potential, but ultimately absent, elements as the conversation moves along. We find similar phenomena in the drawing process.

In drawing, the conversation takes place between the artist and the artwork, and, like any dialogue, moves on several levels at once. The precondition for establishing this dialogue is attainment of the creative condition described above, as this allows subconscious material to become more easily accessible because the past, present and future are in flux. Paradoxically, awareness of the body itself is also weakened: the body feels absent. The artist enters a state of mind full of wondering, excitement and free association, very similar to what is experienced in dreams (Csikszentmihalyi, 1996). The artist enters a state of mind full of wondering, excitement and free association, very similar to what is experienced in dreams during the "rapid eye movement" period of sleep. (Virilio, 1984) 
It is possible to induce this state of mind by using techniques to block out schematic thinking. Examples of common techniques include drawing motifs upside down or looking only at the motif and not the sheet of paper. The latter technique reduces the artist's control over the lines on the paper. Another technique worth mentioning is that of focusing on the empty spaces between objects, as these spaces cannot be given linguistic identities - they can only be seen as shapes (Edwards, 1987).

This kind of non-focal vision allows an unconscious imagining of things that are not physically present, but are sensed and hinted at by traces in the drawing. This gives the artist a repertoire of potential options that are stored in his or her short-term memory, making a foundation for the next move in the drawing process.

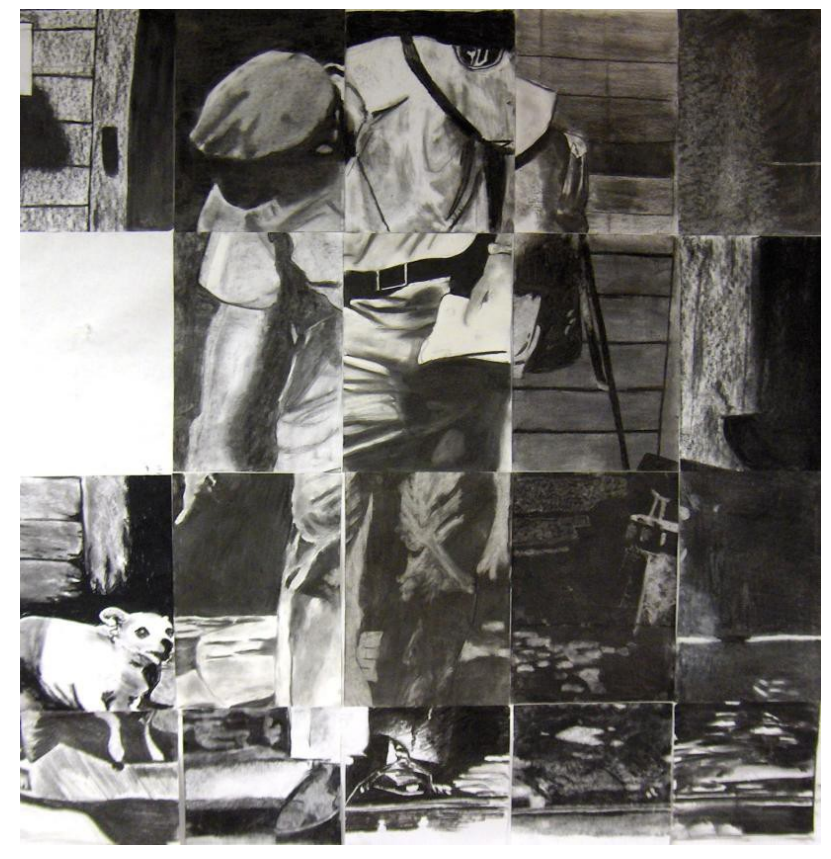

Figure 8. Collective student work, 2004. Each part of the drawing is enlarged from a small scale and drawn without knowledge of the original complete picture.

When speaking, we mentally "sketch out" options for moving the discussion forwards in the short breaks taken to draw breath, which are often only a fraction of a second long. When drawing, the artist collects in the mind a vocabulary of patterns which, step by step, are used to build up convincing gestalts that ultimately rest on the artist's imagination. This is where artistic perception, which combines analytical and synthetic vision, is necessary in order to generate different potential courses of action. These form a repertoire of visual patterns from which the artist can choose.

\section{Holistic contexts and structures}

The imagination investigates the different shapes in a motif in order to capture and re-create the shapes' gestalt. The objective is to elaborate a composition that will integrate all the details into a whole.

This is where the artist exercises his intelligence in order to help the eyes - via their movements on the observed motif - finds the paths the pencil is to take in its wandering on the paper. The artist resembles a blind person accumulating points of contact with a shape by feeling it out point for point in order to acquire knowledge about it - knowledge which can help him reconstruct the structure as a whole. (Valery, 1965: 95) Author's translation. 


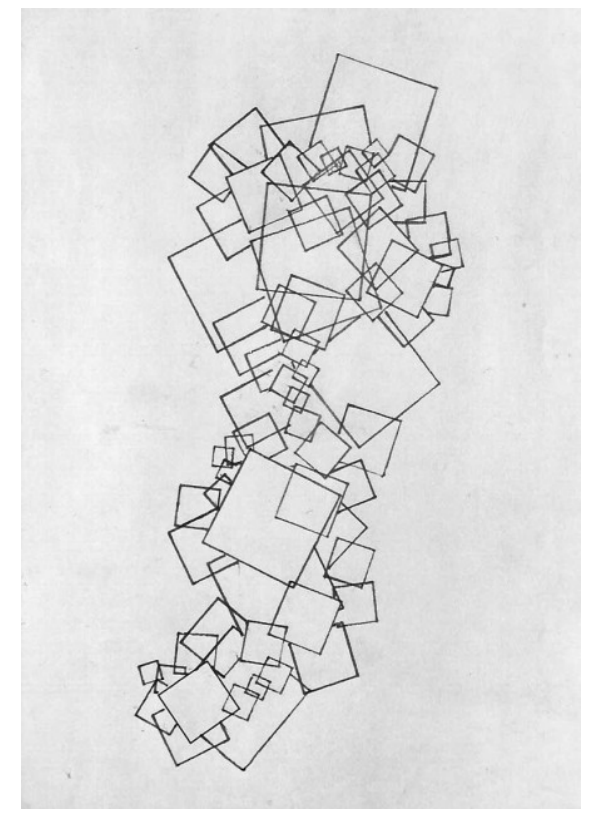

Figure 9. Anonymous student work, 2002. Free composition task: Creating relationships between parts to identify a meaningful structure by using one module displaced in the picture space, repetition, and proportional and position changes.

The method used by the artist is the same as that used by a blind person who uses a stick to navigate: both are using the body as a unit of measurement. While the device used may appear to differ (the blind person relies on a stick, the artist uses sight), both the stick and sight are used as an extension of the body. Gestalt psychologists say that the process of achieving a holistic structure follows from the human need to perceive things as complete entities (see Fig. 9 and 10). The British-Hungarian philosopher Michael Polanyi describes the underlying process that structures the way to holistic gestalt. According to Polanyi, unarticulated knowledge, or tacit knowledge, is active in this process. The process consists of two steps: one that is subordinate and one that is essential.

The relation between the two is such that we must listen to the former in order to understand the latter. We see the entirety, but in order to understand it we must turn from it and instead to the individual parts. (Polanyi, 1962: 615).

When drawing a motif, my strategy is the opposite of that adopted by most beginners: I focus on the motif's surroundings. This involves focusing on the "negative" or interstitial shapes that surround the motif. Only when I have become familiar with several of these can I discover the relationship between foreground and background and perceive the motif in its entirety as a drawing. Throughout the process my perception shifts between focal and non-focal vision in a dialectic process: A waits for B to speak etc. If we hear the same bell ring several times, it becomes possible to hear different sound values. We register the sounds and structure them in relation to one another as new sounds follow. The totality of the sounds becomes greater than the sum of the individual sounds. If we follow Paul Valery's description of the artist's work, we can observe similar developments in the drawing process. Valery writes that the artist collects information about the motif by searching and feeling it out with his eyes, point by point. The first registration creates an expectation of the second registration; the second creates an expectation of the third, and so on. These are temporarily internalised as alternative patterns or as possible combinations, until the expectation of a larger gestalt fuses some of the elements into a new synthesis, only finally to make them concrete and express the artist's experience of the motif as an undivided whole. 
"We know the first term only by relying on our awareness of it for attending to the second" ". (Polanyi, 1966: 10).

"We know more than we can say, but we cannot say anything without listening to what we cannot say." (Polanyi, 1966: 4)

In other words, there is an unconscious cognitive processing of what is registered in the short-term memory. Time is a factor in this context.

Polanyi describes this two-stage mechanism of recognition as "indwelling", and labels the stages "internalisation" and "externalisation" (Polanyi, 1969). The time required from the moment of registration (or internalisation in Polanyi's terminology), through cognitive processing and translation, to the realisation of a graphic representational schema represents an "incubation period" in the drawing process. During this time, the artist "works" subconsciously on virtually structuring the internalised parts of the drawing process on the basis of alternative solutions. By concentrating fully, the process is continued until the satisfactory expectation of a synthetic gestalt is achieved: a composition in which the individual parts are integrated and find their place. This is the moment that follows incubation, namely "illumination", or what Polanyi calls "externalisation", where a complete and structured solution appears.

\section{Non-focal sight and ambiguity}

The prominent Norwegian composer Arne Nordheim once said that it was best for an artist is to be "neither fish nor fowl". Of course, most people find it more comfortable to know who they are. Nordheim's metaphor tells us something about what it is like to work with creative processes. Our brain's "sorting programme" locks our everyday perceptions into an unambiguous, functional and routine interpretation of sensory stimuli. The human brain does not tolerate uncertainty well, preferring safe and automatic confirmation of its own ready-made interpretative models. This may be the result of a deeply rooted evolutionary survival instinct and the brain's need to respond quickly.

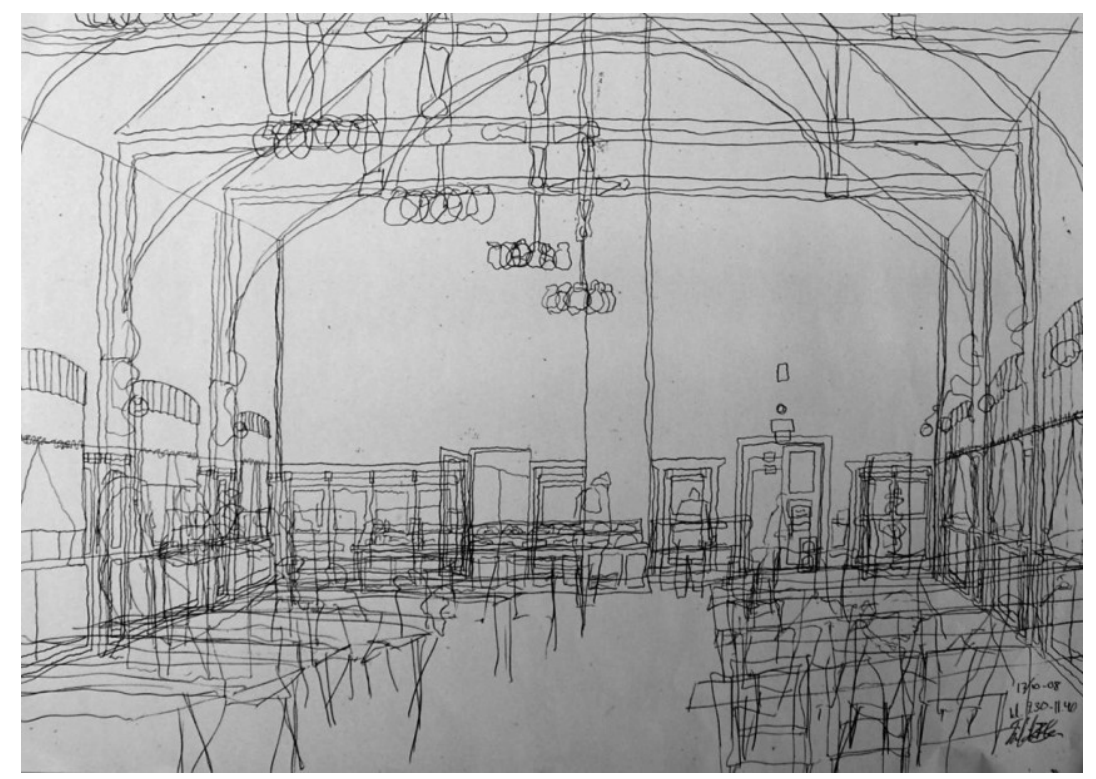

Figure 10: Student work by Fredrik: Economics Cafeteria in As, 2008. Perspective drawing assignment: Use lines alone to capture and translate a space as a whole using negative space, lines angles, registering proportions by eye, without forgetting to enter the creative mode and "becoming one" with the motif. 
Perception as part of shaping something new differs from everyday perception in that it is a creative act that lingers at the moment of perception itself. The act of perception acquires a meditative trait in which focal and non-focal vision alternate. Non-focal vision allows the artist an ambiguous interpretation of the sensory stimuli.

The crux of the matter is that the artist needs to be able to see the forest despite all the trees, i.e., "seeing the tree and the forest simultaneously." Although this is impossible according to psychological theories of perception, artists such as Paul Klee and the psychologist Anton Ehrenzweig have stressed that the artist is able to see both at the same time by using non-focal vision. This form of attention allows the viewer to capture totalities of conflicting and paradoxical data. We can assume that the movements of the eye range in a highly "democratic" fashion over the visual field, $c f$. the comparisons of eye movements recorded by psychologist Stine Vogt in her study of how laymen and artists register motifs (Vogt, 2006).

Perspective drawing entails an ability to see through and on the picture plane simultaneously. Drawing interstitial spaces requires an ability to alternate between seeing shape and background, while seeing both at the same time. The same applies to the perception of light and shadow: the artist looks at the one in order to draw the other. By fragmenting the motif, it becomes possible to see its content both as an abstract form and as a figurative motif. Further ambiguity arises where observed motifs become fused with perceptual stimuli and memorised images.

In her article "Is drawing language?" Karen Raney (1997) distinguishes two significant aspects of this process: firstly, the ambiguity that permits the artist to hold on to more than one thought at a time, and secondly, uncertainty. Uncertainty here refers to the configuration of shapes, which remain unfixed and subject to re-assessment in the artist's ongoing attempt at achieving a synthesis. The artist's unconscious scanning of the entire picture plane, without differentiation between form and background, is a "wide-focused" or "non-focal gaze", which hovers in an uncertain and undefined manner because it aims to capture a motif in relation to the shapes that surround it (Ehrenzweig, 1974). This facilitates what I like to call the "research" space of trial and error, which is repeated in several stages during the development of the drawing. This is where the multiple relationships that constitute a completed drawing are created.

Karen Raney points out an interesting consequence of both ambiguity and uncertainty in the drawing process, namely that the brain is forced to complete the image. This observation becomes all the more relevant when we link it to Polanyi's explanatory model (Polanyi, 1969). Completion consists of a cognitive, subconscious processing of information in which we cannot conclude, but must listen in order to continue to act on the drawing and find our way to the completed mentalisation or gestalt.

\section{So what?}

Unlike much literature on drawing techniques, this article highlights the mental process in the act of drawing from a cognitive and emotional perspective. The reflections presented invite the reader to understand drawing in an extended way. In addition to the visual perception in the drawing process, the artist also benefits from opening all the senses in order to be in the body-mind relationship. The way I see it, in drawing education there is a need for recognizing the role of embodied knowledge in the identification of a motif. According to this way of thinking, an important challenge for the teacher is to motivate students to enter the "creative mode" in the drawing process. This state of mind, will inhibit the brain's stereotypical focus on the motif, and facilitate an interpretation of the motif as 
fragments of forms, thereby opening for a creative process where different levels of consciousness are combined to produce new insight. Hopefully, these reflections provide some new perspectives in terms of how a drawing process can be approached and structured, as well as how we can understand ourselves as subjects through a "head over heels" thought process in the act of drawing.

\section{Presentation of contributor}

Christian Montarou, born in 1948 in Le Mans, France. Painter and Assistant Professor at the Department of Landscape Architecture and Spatial Planning, The Norwegian University of Life Sciences (UMB). As a painter, Montarou has created numerous public artworks and is represented in several of the main art institutions in Norway. As a lecturer, he is responsible for a drawing teaching program that makes up the basis of the three first compulsory years of the landscape architecture education.

\section{References}

Blanchot, M. (1955). L'espace littéraire, Paris: Gallimard.

Carman, T. (1999). Merleau-Ponty`s concept of the body schema. Philosophical Topics

27 (2), 14-20. Barnard College, Columbia University.

Csikszentmihalyi, M. (1996). Flow - den optimala upplevelsens psykologi. Stockholm: Natur \& Kultur.

Collins, J., Mayblin, B. (1998). Derrida for beginners, Cambridge: Icon Books Ltd.

Edwards, B. (1987) Bruk kunstneren i deg. Oslo: Grøndahl \& Søn.

Darras B. (1998). L'image, une vue de l'esprit. Étude comparée de la pensée figurative et de la pensée visuelle : Recherches de communication $\mathrm{nr} 9$.

Derrida, J. (1990). L'autoportrait et autres ruines. Mémoires d'aveugle. Paris: Réunion des Musées Nationaux.

Ehrenzweig, A. (1974). L'ordre caché de l'art. Paris: Gallimard.

Fonagy, P., Gergely G. \& Jurist E. (2002). Affect regulation, mentalisation and the development of the self. New York: Other Press.

Fustier, M. (1975). Exercices Pratiques de Créativité. Initiation a l'Heuristique Fonctionnelle. Lyon: S.M.E.

Gombrich, E. H. (1987). L'art et l'illusion. Paris: Gallimard.

Jung, C.G. (1964). Dialectique du moi et de l'inconscient. Paris: Gallimard.

Kjørup, S. (1995). Hvorfor smiler Mons Lisa? Roskilde Universitetsforlag.

Krogh, C. (1917). Epigraph. Numer nr 1.

Lacan, J. (1949). Le stade du miroir comme formateur de la fonction du Je telle qu'elle nous est révélée dans l'expérience psychanalytique. Espaces Lacan. Accessed 11 November 2010 from

http://pagesperso-orange.fr/espace.freud/topos/psycha/psysem/miroir.htm

Lakoff, G., Johnson, M. (2003). Hverdagslivets metaforer, fornuft, følelser og menneskehjernen. Oslo: Pax Forlag A/S.

Lowenfeld V. (1970). Creative and mental growth. London: MacMillan Company.

Merleau-Ponty, M. (1945). La phénoménologie de la perception. Paris. Gallimard.

Montarou, C. (2011). Krokitegning og kroppskognisjon. Numer 88(02), 6-9.

Polanyi, M. (1962).Tacit Knowing: It's bearing on Some Problems of Philosophy. Review of Modern Physics, 84 nr 4, p. 601-616.

Polanyi, M. (1966). The Tacit Dimension. Gloucester, MA: Peter Smith

Polanyi, M. (1969). On body and mind. The New Scholasticism. 43 (2), 195-204. Accessed 21 November 2011 from http://echo.iat.sfu.ca/library/polanyi 69 body mind.pdf

Raney, K. (1997). Is drawing a language? Tracey-Drawing and visualization research. Online journal. Accessed 11 November 2010 from:

http://www.lboro.ac.uk/departments/sota/tracey/journal/idal/raney.html 
Sandqvist, T. (1994). Från hieroglyfen til flasktorkaren, Stockholm/Stehag:Brutus Østling, p.27

Sandqvist, T. (1992). Bilden år i bilden, Stockholm/Stehag: Brutus Østling

Skårderud, F. (2008). Mentalisering - Et nytt teoretisk og terapeutisk begrep. Tidsskrift for Den norske legeforening. 2008(128), 1066-9.

Valery, P. (1965). Degas, Danse, Dessin. Idées/arts. Paris: Gallimard.

Virilio, P. (1984). L espace critique, essais. Paris: Christian Bourgois.

Vogt, S. (2006). Perceptual processing in artists and laymen.PhD thesis.Oslo University: Institute of Psychology.

Wilsom, A. R., Foglia L. (2011).Embodied Cognition. Stanford Encyclopedia of Philosophy. Accessed 23 October 2011 from: http://plato.stanford.edu/entries/embodied-cognition/ 